\title{
Erratum to: Cadmium nanoclusters in a protein matrix: Synthesis, characterization, and application in targeted drug delivery and cellular imaging
}

\author{
Morteza Sarparast ${ }^{1, \S}$, Abolhassan Noori ${ }^{1, \S}$, Hoda llkhani ${ }^{1}$, S. Zahra Bathaie ${ }^{2}$, Maher F. El-Kady ${ }^{3,4}$, Lisa J. Wang ${ }^{3}$, \\ Huong Pham ${ }^{3}$, Kristofer L. Marsh ${ }^{3}$, Richard B. Kaner ${ }^{3,5}(\varangle)$, and Mir F. Mousavi ${ }^{1,3}(\varangle \Delta)$ \\ ${ }^{1}$ Department of Chemistry, Tarbiat Modares University, Tehran 14115-175, Iran \\ ${ }^{2}$ Department of Clinical Biochemistry, Faculty of Medical Sciences, Tarbiat Modares University, Tehran 14115-111, Iran \\ ${ }^{3}$ Department of Chemistry and Biochemistry, University of California, Los Angeles, Los Angeles, CA 90095, USA \\ ${ }^{4}$ Department of Chemistry, Faculty of Science, Cairo University, Giza 12613, Egypt \\ ${ }^{5}$ California NanoSystems Institute, University of California, Los Angeles, Los Angeles, CA 90095, USA \\ ${ }^{\S}$ Morteza Sarparast and Abolhassan Noori contributed equally to this work. \\ (C) Tsinghua University Press and Springer-Verlag GmbH Germany, part of Springer Nature 2018
}

\section{Erratum to}

Nano Research 2016, 9(11): 3229-3246

https://doi.org/10.1007/s12274-016-1201-z

The Electronic Supplementary Material available online erroneously only contains the first six pages of the entire supplementary material file. You will find the entire supplementary material file online linked to this publisher's erratum. The publisher apologizes to the authors and readers for this mistake.

Electronic Supplementary Material: Supplementary material (detailed description on procedures, and further characterizations, including synthesis, optimization, and characterization of $\mathrm{Cd}_{\mathrm{NCs}}, \mathrm{HA}-\mathrm{Cd}_{\mathrm{NCs}}$, and DOX$\mathrm{HA}-\mathrm{Cd}_{\mathrm{NCs}}$; calculating quantum yield; a Jellium model for assigning the most valid number of the atoms in the $\mathrm{NCs}$; drug loading and release; cellular uptake and cytotoxicity) is available in the online version of this article at https://doi.org/10.1007/s12274-016-1201-z.

The online version of the original article can be found at

https://doi.org/10.1007/s12274-016-1201-z

Address correspondence to Richard B. Kaner, kaner@chem.ucla.edu; Mir F. Mousavi, mousavim@modares.ac.ir 